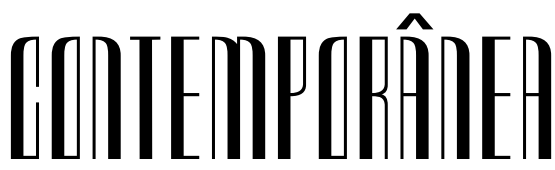

http://dx.doi.org/10.4322/2316-1329.089

Contemporânea

v. 9 , n. 1 p. $229-252$

Jan.-Jun. 2019

Artigos

\section{"Moda, eu faço a minha": a circulação de símbolos globais de moda entre grupos de baixa renda.}

Ana Lucia de Castro'

Beatriz Sumaya M. Haddad²

Resumo: Este artigo tem como objetivo contribuir para a discussão da dimensão simbólica do consumo, enfatizando especificamente o consumo de referências de moda por grupos de baixa renda, com base em trabalho de campo - envolvendo entrevistas individuais, registro de observações e realização de grupos focais - realizado entre moradores de um bairro na periferia de Santo André-SP. Dentre os aspectos relativos aos discursos sobre consumo, enfocamos as formas de apropriações de peças originais ou de réplicas e a oposição entre moda e estilo como categorias acionadas nos discursos dos entrevistados ao se referirem às suas motivações como consumidores. Busca-se analisar como a noção de estilo - associada à ideia de escolha e acionada pelos entrevistados para se oporem à de moda - é constitutiva de um ideário que preconiza o cálculo e as escolhas individuais como características das sociedades atuais.

Palavras-chave: moda, estilo, consumo, fronteiras simbólicas

\footnotetext{
$1 \quad$ Faculdade de Ciências e Letras de Araraquara - Universidade Estadual Paulista - (UNESP) - Araraquara - Brasil - castroanalucia75@gmail.com

2 Faculdade de Ciências e Letras de Araraquara - Universidade Estadual Paulista - (UNESP) - Araraquara - Brasil - biasumaya@yahoo.com.br
} 


\section{Fashion and style as speeches: appropriation of symbols globalizing fash- ion for low-income groups}

Abstract. This article aims to contribute to the discussion of the symbolic dimension of consumption, specifically emphasizing the consumption of fashion references for low-income groups, from field work - involving individual interviews, observation reports and conducting focus groups - held between residents of a neighborhood on the outskirts of Santo André- SP. Among the aspects of the discourse on consumption, we focused on the forms of appropriation of original or replicas and the opposition between fashion and style as driven categories in the interviews when referring to their motivations as consumers. The aim is to analyze how the notion of style - associated with the idea of choice and driven by respondents to oppose fashion - is constitutive of an ideology that advocates the calculation and individual choices as characteristic of contemporary societies.

Keywords: fashion, style, consumption, symbolic borders

\section{Introduç̃̃o}

Tendo como principal preocupação contribuir para a discussão acerca da dimensão simbólica do consumo, este artigo busca enfatizar, especificamente, 0 consumo de referências de moda por grupos de baixa renda, baseado em pesquisa de campo realizada entre moradores de um bairro na periferia de Santo André-SP. No tocante aos discursos sobre consumo, enfocamos as formas de apropriações de peças originais ou de réplicas e a oposição entre moda e estilo como categorias acionadas nos discursos dos entrevistados ao se referirem às suas motivações como consumidores. Assim, busca-se analisar como a noção de estilo - associada à ideia de escolha e acionada pelos entrevistados para se oporem à de moda - é constitutiva de um ideário que preconiza o cálculo e as escolhas individuais como características das sociedades atuais.

Tomamos como referências de moda as peças do vestuário de marcas consideradas mundiais, que apresentam como característica o alcance simbólico por meio de seus slogans. Nesse sentido, as marcas esportivas ${ }^{3}$ - relacionadas principalmente ao futebol (esporte mundial) -, que têm símbolos reconhecidos mundialmente e são muito difundidos em peças de vestuário, ganham ênfase na pesquisa de campo. Assim, durante o trabalho de campo, a mobilização

3 Vale destacar a aproximação com o trabalho de Mizrahi (2014), que também apontou a valorização de marcas esportivas no universo do funk do Rio de janeiro. 
desses símbolos, difundidos com muita regularidade pela mídia, constituiu-se numa estratégia de aproximação das questões que pretendíamos circundar no decorrer das entrevistas. Além disso, concentramo-nos nas relações desses indivíduos com o consumo de moda, ou seja, onde e porque compram produtos considerados "da moda" e com base em qual premissa fazem suas escolhas.

A pesquisa de campo foi realizada em uma comunidade de baixa renda denominada Núcleo Jardim Santo André, localizada na cidade de Santo André-SP. Os indivíduos pesquisados são moradores do local, de ambos os sexos, e de variadas idades - entre 15 e 60 anos. Ao denominarmos essa população como de "baixa renda", apoiamo-nos em uma pesquisa sobre o perfil socioeconômico dos moradores do bairro, realizada pela área social da $\mathrm{CDHU}^{4}$, a qual apontou um percentual de domicílios com renda familiar per capita mensal baixa bem maior do que a média nacional. Significativa parcela das famílias residentes nos núcleos de favela do bairro $(42,5 \%)$ conta com um valor de até meio salário mínimo como renda familiar per capita mensal, enquanto no Brasil, segundo o censo de 2010, 24,02\% dos domicílios brasileiros e 15,40\% dos localizados no Sudeste contam com uma renda familiar per capita de até meio salário mínimo (Castro, 2016: 107)

Um roteiro de questões previamente elaborado foi utilizado com o objetivo de guiar as entrevistas, que aconteceram, em um primeiro momento, de forma individual, prezando pela fluidez das conversas. Estas foram realizadas no decorrer do reconhecimento do campo - enquanto andávamos pelas ruas e vielas da comunidade, empenhávamo-nos em efetuar os primeiros contatos com os moradores. Além disso, contamos com o apoio dos funcionários da sede do $\mathrm{CDHU}$, que, devido ao vasto conhecimento do local, auxiliaram-nos na aproximação com alguns residentes ${ }^{5}$.

Em um segundo momento, realizamos grupos focais previstos no projeto inicial dessa pesquisa. A técnica de coleta de informações denominada Grupo Focal consiste em reunir um grupo de 8 a 15 informantes, um coordenador e um relator. A discussão, conduzida pelo coordenador, é pautada por um roteiro pré-estruturado de questões e ao relator cabe a tarefa de anotar as impressões, reações e tudo aquilo que diz respeito ao não verbalizado. O perfil dos informantes reunidos é definido com critério intencional, em sintonia com os

4 CDHU (Companhia de Desenvolvimento Habitacional e Urbano). Para maior detalhamento desta pesquisa, que realizou amplo levantamento quantitativo sobre as condições e expectativa de vida no bairro, ver Castro (2016).

5 Nessa fase da pesquisa, entrevistamos o total de oito mulheres e dois homens, com idades variadas entre 18 e 60 anos. 
interesses da pesquisa. A vantagem dessa técnica é que se foca na exploração de temas específicos, além do que, por ser em grupo, acaba motivando todos os membros a exporem suas ideias, numa espécie de conversa, com tom descontraído e informal.

Foram realizados dois grupos focais, organizados com os seguintes critérios de homogeneidade: no primeiro deles, interessava-nos o fato de ser morador do empreendimento mais recente entregue pela CDHU e responsável pelas compras que abastecem a casa e, no segundo deles, interessava-nos a idade dos integrantes ${ }^{6}$, pois percebemos se tratar de variável chave quando o assunto é consumo de moda. Nesta experiência participaram jovens de 15 a 25 anos. Ambos os grupos focais foram realizados na associação de moradores do bairro.

O Núcleo Jardim Santo André é constituído de um aglomerado de cinco favelas: Dominicanos, Lamartine, Cruzado, Campineiros, Missionários e Toledanos. Desde a década de 1980, a região sofre a intervenção do CDHU, após a construção de unidades habitacionais e da urbanização das favelas.

Apesar desse tempo de intervenção, a quantidade de pessoas vivendo em situações precárias, em barracos de madeirite, próximos a córregos e esgotos a céu aberto ainda é muito grande. Durante o trabalho de campo, foi inevitável observar os cenários tão díspares em convivência: favelas e conjuntos habitacionais em fragmentos de espaço urbanizados.

6 Deparamo-nos com a dificuldade em reunir os indivíduos para a realização dos grupos focal, pois muitos se mostravam receosos por não compreender a intenção real do grupo, mesmo depois que nos dedicávamos a explicar. Além disso, o fato de os indivíduos trabalharem em horários diversificados também foi outro problema enfrentado na tentativa de reuni-los para o "bate papo", e, devido a essa dificuldade, optamos por realizar um grupo durante o fim de semana. Porém, ainda assim a participação foi pequena, e pudemos contar com três moradores, duas mulheres e um homem. O segundo grupo focal foi restrito à participação de jovens (de 15 a 25 anos), e foi realizado em dia de semana. Contamos com um número satisfatório de participantes, totalizando nove indivíduos (sete meninas e dois meninos). Para tanto, pudemos contar com o auxílio da presidente da Associação de Moradores, que contatou os jovens da região. Além disso, o grupo foi realizado em período de férias escolares, o que facilitou a presença de um número ideal de participantes para a realização do grupo focal. 
Figura 1 - Os "predinhos" contrastando com o aglomerado de favelas ao fundo

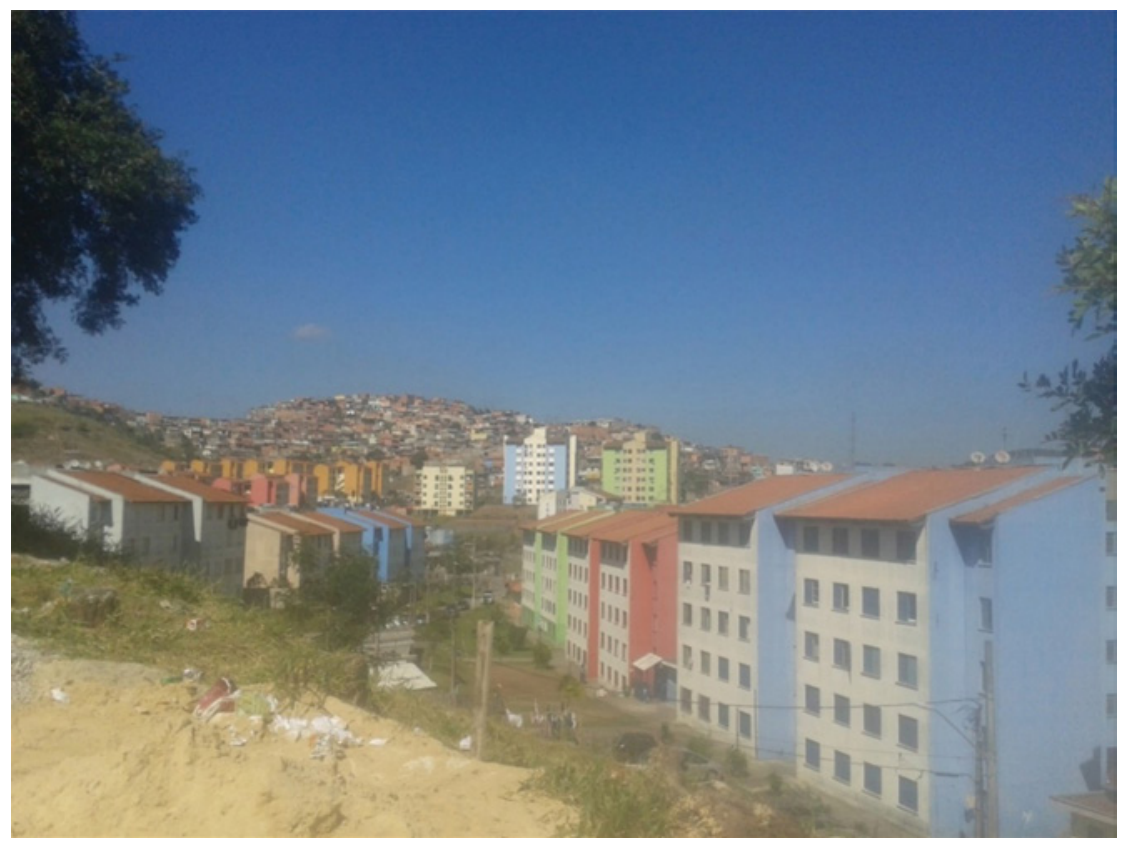

Fonte: Autoras (foto obtida no trabalho de campo)

Figura 2 - Barracos de madeirite, bastante comuns na região

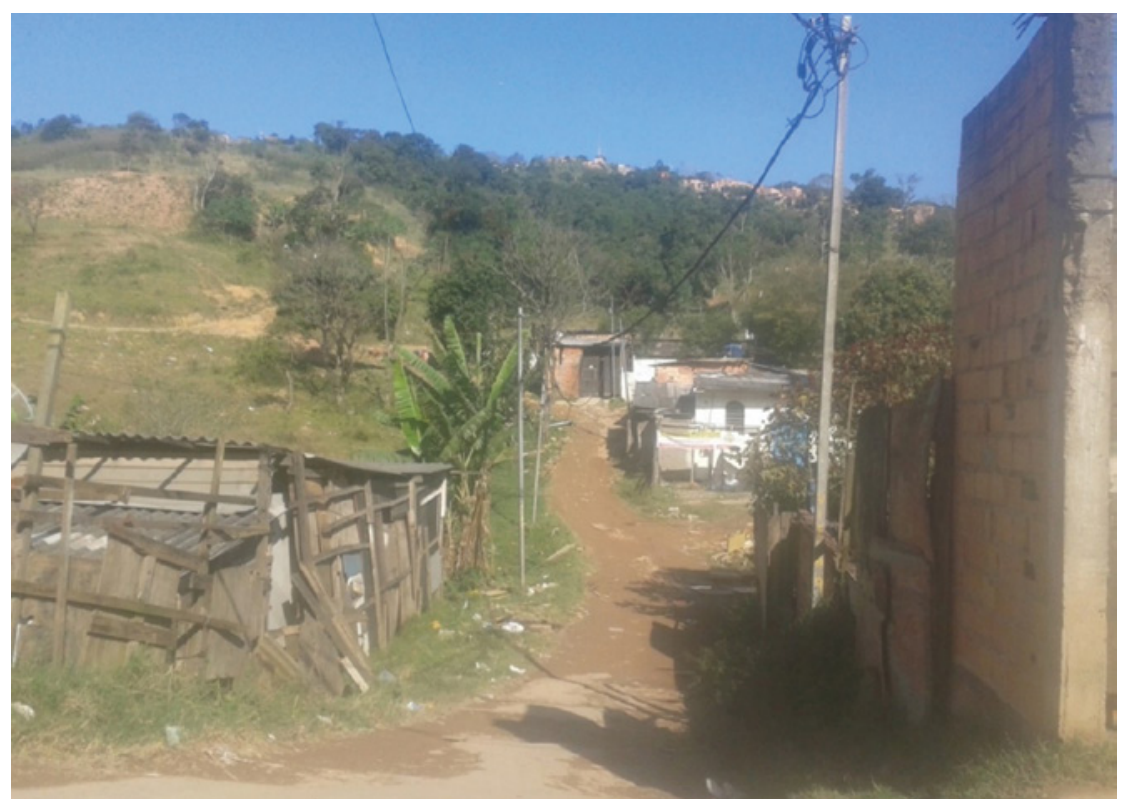

Fonte: Autoras (foto obtida no trabalho de campo) 


\section{Modos de consumo e mediações culturais}

O campo da moda é composto por diversos atores e organizações que atuam em algumas instâncias, como produção, divulgação, legitimação e consumidores (Leitão, 2007). A produção é composta pelos pesquisadores de tendência, estilistas, modelistas, costureiros e funcionários ligados à essa etapa. A imprensa e a mídia são instâncias da divulgação, e, nesse âmbito, especificamente para os indivíduos observados neste estudo, encontramos as novelas como grandes difusoras de tendência. Porém, para que o marketing encontre sucesso, é fundamental que o produto ganhe legitimidade junto ao público, e, para isso, atualmente, as celebridades ganham um papel importante, participando de comerciais e fazendo uso de produtos específicos nas novelas.

O consumidor também exerce papel fundamental e ativo nesse contexto, ao escolher, usufruir e disseminar o uso de certo produto. A aceitação do consumidor é imprescindível para que a tendência seja legitimada. Assim, a análise do consumo de referências de moda aponta para a necessária ambiguidade: ao mesmo tempo que ocorre imposição ao público por uma indústria, também se configura em uma maneira de comunicar uma posição social, ou, como coloca Crane, ao se referir à moda, trata-se de "forma de comportamento por meio do qual os consumidores expressam as percepções de suas identidades e suas conexões com grupos específicos" (Crane, 2011: 14).

A discussão sobre consumo deve levar em conta as duas dimensões do fenômeno, relevando tanto o seu caráter impositivo como as possibilidades, por ele abertas, de elaborar processos de construção de identidades. Canclini (2008) aponta três perspectivas que marcam a análise sobre o tema: a primeira é a da "racionalidade econômica", na qual o consumo seria o momento em que "se completa um processo iniciado com a geração de produtos, em que se realiza a expansão do capital e se reproduz a força do trabalho" (Canclini, 2008: 61). Nessa concepção, não é o gosto ou as necessidades individuais que determinam as compras, mas as "grandes estruturas de administração do capital".

Outra perspectiva é a de que a relação entre produtores e consumidores ocorre por meio de uma "racionalidade sociopolítica interativa", na qual o conflito entre classes se revela um cenário de disputas, e os produtores devem atrair o consumidor pela racionalidade.

A terceira concepção acerca do consumo, apresentada por Canclini, chama a atenção para "aspectos simbólicos e estéticos da racionalidade consumidora", visão sustentada pelos que estudam o "consumo como lugar de diferenciação e distinção entre classes e grupo", 
Os textos de Pierre Bourdieu, Arjun Appadurai e Stuart Ewen, entre outros, mostram que nas sociedades contemporâneas boa parte da racionalidade das relações sociais se constrói, mais do que na luta pelos meios de produção, pela disputa em relação à apropriação dos meios de distinção simbólica. Há uma coerência entre os lugares onde os membros de uma classe e até de uma fração de classe se alimentam, estudam, habitam, passam as férias, naquilo que leem e desfrutam, em como se informam e no que transmite aos outros. Essa coerência emerge quando a visão socioantropológica busca compreender em conjunto tais cenários. A lógica que rege a apropriação dos bens como objetos de distinção não é a da satisfação de necessidades, mas sim a da escassez desses bens e da impossibilidade de que outros o possuam. (Canclini, 2008: 62)

Partindo de ampla base empírica, Bourdieu defende a tese de que o consumo (sobretudo o consumo alimentar, vestuário e cultural) é estratégia de distinção social, mecanismo pelo qual os indivíduos e grupos evidenciam marcas de pertencimento a determinados círculos e, ao mesmo tempo, afastam-se de outros, reforçando fronteiras simbólicas. O principal legado de Bourdieu, vale lembrar, reside no apontamento dos sistemas classificatórios extremamente hierarquizantes que marcam as sociedades capitalistas ocidentais e do exercício do poder simbólico nas práticas culturais (incluindo o consumo). Parte da ideia de que, nas sociedades de classes hierarquizadas, a lógica que imprime sentido às práticas cotidianas, dentre elas o consumo, é a da distinção-imitação, num movimento constante de busca de afastamento dos "de baixo" para parecer com os "de cima". E seria no corpo, conforme Bourdieu, que poderíamos encontrar o gosto de classe que se mostra de várias maneiras, nas formas, nas dimensões, no modo de tratá-lo e cuidá-lo, tendo como princípio gerador das práticas o habitus, produzido e incorporado no processo de socialização e, portanto, assentado em condições materiais de existência, estrutura estruturante e estruturada pelas práticas e representações.

A perspectiva analítica que enfatiza a dimensão simbólica dos bens e suas apropriações tem um importante marco no trabalho de Jean Baudrillard, quem aponta o caráter sígnico do objeto, o qual passa a ser visto não mais apenas como um produto ou uma mercadoria, mas um signo inserido num sistema de signos de status (Baudrillard, 1973). Ainda que preocupado em denunciar o consumo como o elemento central e redutor das sociedades capitalistas, Baudrillard contribui para a construção de uma perspectiva sobre o consumo que aponta para além da sua dimensão prático-utilitarista. Com base na semiologia, 
desvenda-nos outros nexos da problemática, entendendo que o consumo supõe a manipulação ativa de signos e que na sociedade capitalista tardia o signo e a mercadoria teriam se juntado para formar a mercadoria-signo, conceito cunhado para enfatizar o desligamento das mercadorias de sua utilidade funcional (Baudrillard, 1985).

O trabalho desenvolvido por Mary Douglas (2004), ao lado do economista Baron Irshwood, também deve ser apontado como referência para a construção da perspectiva aqui delineada. Segundo os autores, caberia ao antropólogo desvendar os valores, socialmente construídos, subjacentes ao consumo dos bens, os quais configurariam a dimensão material de um ritual que ocorreria cotidianamente entre as pessoas, cujo principal elemento de sustentação seria a fixação dos significados na vida social. Nesta linha, os bens se configurariam como "pontes" ou "cercas", capazes de estabelecer elos de pertença e/ou fronteiras simbólicas entre os sujeitos e os grupos. Pautados pela noção de que toda prática diária se ampara em um sistema simbólico, fornecedor dos referenciais sobre as maneiras de agir, e, principalmente, de significar algo para os outros, os autores defendem que as mercadorias estariam, nesse sentido, exercendo o papel de comunicadores, e mais, seriam o material simbólico utilizado pelos consumidores na construção de um universo inteligível (Douglas; Ishwood, 2004).

Se vem sendo dito que a função essencial da linguagem é sua capacidade para a poesia, assumiremos que a função essencial do consumo é sua capacidade para dar sentido. Duvidemos da ideia da irracionalidade do consumidor. Duvidemos de que as mercadorias servem para comer, vestir-se e se proteger. Duvidemos de sua utilidade e tentemos colocar em troca a ideia de que as mercadorias servem para pensar. Aprendamos a tratá-las como meio não verbal da faculdade criativa do gênero humano. (Douglas; Isherwood, 2004: 77)

Interessa-nos pensar o consumo como "processo social produtor de sentidos e de identidades, construídos pelo valor simbólico socialmente atribuído às mercadorias, e não ao seu valor de uso" (Castro; Capelaro, 2009: 7). Neste sentido, vale recorrer à crítica às análises que reduzem as relações econômicas entre os homens à dimensão prático-utilitarista, a qual tem importante ponto de apoio nas reflexões de Marshall Sahlins, quem aponta criticamente para a necessidade de construção de um olhar analítico que se volte para a ordem cognitiva complexa de categorias culturais e suas relações na discussão das 
apropriações e interdições de bens de consumo, a exemplo de como ele próprio opera no ensaio La penseé Bourgeoise (Sahlins, 2003).

Em Cosmologias do Capitalismo (2004), o autor amplia e refina o argumento de que as trocas de mercadorias são movidas, sobretudo, por uma dimensão que escapa aos imperativos de suas funções prático-utilitaristas, ao demonstrar que os principais produtos que moveram as relações econômicas entre os países hegemônicos no Século XIX (chá, ópio e sândalo) muito se afastavam da ideia de necessidade, como vem sendo sustentado numa perspectiva prático-utilitarista.

Outra importante contribuição para perspectivas analíticas que pretendem desvendar os múltiplos sentidos do consumo reside no trabalho de Daniel Miller (2002; 2004), quem revê as teorias sobre consumo vigentes, muito marcadas pela perspectiva da condenação moral e, com base na pesquisa etnográfica realizada com donas de casas, residentes em bairro popular no norte de Londres, aponta como principais sentidos construídos pelo ato da compra, a reposição de "laços afetivos" e o "sacrifício" (Miller, 2002). Ao desenvolver a teoria das compras como "sacrifício", o autor aponta que este se consubstanciaria no ato de despesa, pelo qual se consome algo de material, mas se atinge benefícios que nada têm de materiais. Em analogia, as compras de supermercado se configurariam como ato sacrificial, na medida em que transformam a despesa num ritual de devoção para com os membros da família.

Estudar o consumo sob uma perspectiva clássica, que marcou o início do Século XX, remeteria-nos a uma visão de que o consumo é resultado de uma "reprodução social", marcada pela lógica da produção, em que apenas assinala uma realidade intrínseca à disputa de classes e interesses econômicos. Nessa dinâmica, o consumidor seria um mero reprodutor, pois atuaria de forma irracional e impelido a responder aos interesses de grupos específicos.

Porém, ao pensar o consumo sob uma perspectiva que parte do ponto de vista do sujeito, é possível observar que este é, também, esfera de produção de sentido (De Certeau, 1994). Esta perspectiva analítica ancora-se, em boa medida, na Teoria das Mediações, elaborada por Martín-Barbero (1997), quem, ao se contrapor às ideias difundidas pela Escola de Frankfurt, sustenta que é impossível realizar uma análise das formas de comunicação sem levar em consideração os sentidos acionados pela recepção.

Na redefinição da cultura, é fundamental a compreensão de sua natureza comunicativa. Isto é, seu caráter de processo produtor de significações e não de mera circulação de informações, no qual o receptor, portanto, não é um 
simples decodificador daquilo que o emissor depositou na mensagem, mas também um produtor. $O$ desafio apresentado pela indústria cultural aparece com toda a sua densidade no cruzamento dessas duas linhas de renovação que inscrevem a questão cultural no interior do político e a comunicação, na cultura (Martín-Barbero, 1997: 287).

Dessa forma, é impossível compreender o campo da comunicação apenas observando sua produção. Analogamente, a análise do consumo como prática cultural também não pode levar em consideração apenas a esfera da produção de bens. Com base nessa perspectiva - reconhecida como "teoria das mediações” -, torna-se possível uma nova compreensão da produção social de sentindo mediada pelos meios de comunicação e pelo consumo.

Um bom número de estudos sobre comunicação de massa tem mostrado que a hegemonia cultural não se realiza mediante ações verticais, onde os dominadores capturariam os receptores: entre uns e outros se reconhecem mediadores, como a família, o bairro e o grupo de trabalho. Nessas análises deixou-se também de conceber os vínculos entre aqueles que emitem as mensagens e aqueles que as recebem como relações unicamente, de dominação. A comunicação não é eficaz se não inclui também interações de colaboração e transação entre uns e outros. (Canclini, 2008: 60).

A mediação cultural, portanto, pode ser traduzida como um processo que aproxima e imbrica diferentes contextos sociais e culturais, tornando possível a comunicação entre agentes de universos culturais distintos. Ao explicar o processo de mediação, Velho e Kuschnir (2001) sustentam que

Num contínuo processo de negociação da realidade, escolhas são feitas, tendo como referência sistemas simbólicos, crenças e valores, em torno de interesses e objetivos materiais e imateriais dos mais variados tipos. A mediação é uma ação social permanente, nem sempre óbvia, que está presente nos mais variados níveis e processos interativos (Velho; Kuschnir, 2001: 11).

Com base nessas perspectivas analíticas, podemos nos remeter ao nosso campo de pesquisa, refletindo sobre em que medida o consumo pode ser entendido como prática de mediação cultural, ou, ainda, sobre "o consumo como algo mais complexo do que uma relação entre meios manipuladores e dóceis audiências" (Canclini, 2008: 59). Neste sentido, buscamos, nesta reflexão, enfatizar o consumo como um o meio pelo qual os indivíduos "vivem o processo 
de globalização e atualizam-se na vida cotidiana" (Scalco; Pinheiro-Machado, 2010: 325), em um processo relacional, no qual paralelamente à tendência de homogeneização trazida pela universalização das tendências de moda, encontramos um grande interesse pelo âmbito local. Dessa forma, o consumo local ressignifica os símbolos globalizados de acordo com suas realidades singulares, e o estar na moda ou usar roupas de marcas possibilitam a inclusão local no âmbito global e vice-versa. Com base nesta perspectiva teórica, passamos a discutir parte dos dados levantados no decorrer da pesquisa de campo.

\section{Moda x Estilo}

Uma importante questão que emergiu da pesquisa de campo foi acerca da definição facultada à palavra moda, tanto por nós, pesquisadores, como pelos entrevistados.

É senso comum pensar a moda como algo que faz parte do dia a dia apenas de um nicho privilegiado - econômica, cultural e socialmente $₫$ da sociedade. Logo, é muito comum que a palavra moda venha associada à imagem dos grandes desfiles, das supermodelos e de um mundo inatingível à maioria da população que vive à margem de tal realidade.

Nessa perspectiva, o campo da moda é provido de uma estrutura específica que possui um centro que difunde e legitima todas as outras frações da estrutura. Esse centro irradiador é sustentado pela consagração que lhe é atribuída por outras instâncias, ou seja, sua existência e legitimidade são frutos de um reconhecimento e de uma rotulação específica que lhe são conferidas no campo das lutas simbólicas e que lhe atribui poder simbólico.

O poder simbólico é um poder de fazer coisas com palavras. É somente na medida em que é verdadeira, isto é, adequada às coisas, que a descrição faz as coisas. Nesse sentido, o poder simbólico é um poder de consagração ou de rotulação, um poder de consagrar ou revelar coisas que já existem. (Bourdieu, 1990: 167)

Nesse campo de batalha, cabem às pessoas "excluídas da moda" criar seus estilos próprios e portar suas melhores armas contra aqueles que os consideram inapropriados para fazer parte de uma realidade abastada. Isso se destacou na pesquisa de campo quando os entrevistados foram questionados sobre moda - com perguntas como "você segue a moda?", "o que é moda para você?". Eles discursavam sempre na mesma direção, negando a aproximação ou o gosto 
por coisas consideradas da moda e redirecionando a preocupação por seguir a moda a outros indivíduos.

Em uma primeira análise, a rejeição à moda pode ser associada ao discurso de que todos que se preocupam e que dispendem dinheiro com as frivolidades da moda são, assim como aquela, pessoas fúteis e instáveis.

Entre os consumidores de todos os tipos de produtos, os consumidores de moda exibem a imagem mais desfavorável. Estes tendem a ser caracterizados como vítimas, incapazes de controlar seus hábitos de gasto e de resistir à compulsão de comprar roupas ridículas ou horrorosas. (Crane, 2011: 241)

Porém, ao nos ater mais profundamente aos discursos proferidos em campo, foi possível perceber que os indivíduos realizam uma denegação simbólica para se colocar em posição afastada daquilo que ele considera supérfluo e pertencente a outros grupos sociais, valorizando, assim, o nicho a que pertence.

A denegação é uma teoria psicanalítica desenvolvida por Freud, utilizada também por Bourdieu. Para Freud (1976 [1924]), "a negativa constitui um modo de tomar conhecimento do que está reprimido; com efeito, já é uma suspensão da repressão, embora não, naturalmente, uma aceitação do que está reprimido" (Freud, 1976 [1924]: 296). Portanto, o que se nega é exatamente aquilo que está reprimido, e, ao negar, mantém-se o que está reprimido. Nessa perspectiva, ao denegar a moda, ou seja, negar aquilo que já lhe foi anteriormente negado (negar duas vezes), o indivíduo consolida a posição social que lhe foi atribuída no campo das lutas simbólicas.

Como afirma Bourdieu (2004), "o espaço social tende a funcionar como um espaço simbólico, um espaço de estilos de vida e de grupos de estatuto, caracterizado por diferentes estilos de vida" (Bourdieu, 2004: 160), no qual os signos da realidade social servem como distinção. Assim, as "distâncias sociais estão inscritas nos corpos" (Bourdieu, 2004: 155) e são reforçadas constantemente por meio dos discursos.

A moda é, portanto, a priori, caracterizada por uma estrutura dotada de um centro específico que se autoproclama a "verdadeira moda", que tem legitimidade para isso, e que exclui todos aqueles que não pertencem ao campo. Não negamos a existência de tal estrutura, mas a percebemos como um resultado de uma produção de crenças embasadas em discursos que criam tais simbologias sociais. Assim, podemos destituir da moda tais crenças e tratá-la com base em suas engrenagens mais elementares e que constituem sua essência. Quando falamos de moda neste trabalho, portanto, estamos falando daquilo que é efêmero, 
que é novidade, que independente de sua origem - seja nas passarelas, seja nas ruas ou nas novelas -, que celebra o moderno e é desejado como sinônimo de representação de uma determinada posição social. Dessa forma, a moda atinge todos os grupos, de forma particular e específica, mas sempre marcada pelo movimento constante e pela finitude irreversível.

Como anteriormente descrito, os entrevistados negam a preocupação e o uso de roupas tidas como "da moda", valorizando o que denominam de "estilo próprio". A moda é caracterizada pelos sujeitos entrevistados como algo que padroniza os indivíduos e que, por isso, não convém segui-la. Essa concepção é ilustrada no depoimento a seguir:

Pra mim, moda é algo padronizado, que nem eu vi esses tempos na televisão a artista, a atriz usou o brinco tal, o esmalte tal, nos salões todo mundo só queria aquele esmalte, porque a atriz estava usando aquele esmalte. Nas lojas de bijuteria o brinco mais procurado era o brinco tal porque a atriz tal tava usando. Então eu acho que moda é algo que é padronizado, a pessoa vê, cria uma imagem, "eu quero ser igual, quero ter aquilo que a pessoa tem". Isso é moda e eu acho que padronizou e isso que não gosto.?

Esse tipo de percepção sobre a moda é consonante às formulações pioneiras de Simmel, para quem a imitação seria o que sustenta a dinâmica da moda: "ela é imitação de um modelo dado e satisfaz assim a necessidade de apoio social, conduz o indivíduo ao trilho que todos percorrem, fornece o universal, que faz do comportamento de cada indivíduo um simples exemplo" (Simmel, 2008: 24).

Foi possível notar, com base no trabalho de campo, que a palavra moda remete instantaneamente àquilo que é "igual a todos". L. salientou não apreciar a moda: "não gosto de moda. Tipo assim, se eu ver uma pessoa, eu não gosto de me vestir igual a ela." Nessa dinâmica, podemos identificar, de um lado, a moda, aspirando à universalidade, e, de outro, o estilo, oferecendo o discurso da originalidade. Assim, almeja-se substituir a obediência e a imitação daquilo "que está na moda" pela escolha particular incitada pelo estilo individual, como enfatiza F.: (sobre a moda) "eu faço a minha."9

Acreditamos em um contexto em que os indivíduos sustentados pela valorização da individualidade e da "liberdade" - características da modernidade - são levados a repelir o conceito de moda como sinônimo de "aprisionamento" 
e a valorizar o conceito de estilo, carregado de características que possibilitam a livre escolha em um leque muito diversificado de possibilidades. Isso porque a palavra estilo remete a uma maneira singular sobre como os sujeitos pensam e se expressam no contexto social. Por isso, a linha entre o estilo e a identidade pessoal é muito tênue, já que ao buscar um estilo o indivíduo está se esforçando por encontrar também uma identidade: "Eu não sigo (a moda) porque não gosto de ser igual aos outros. Por exemplo, se tem uma blusinha da moda que todo mundo usa eu não gosto de usar, gosto de ser diferente. Eu crio meu estilo diferente." ${ }^{10}$

Pode-se depreender, dentre os discursos e observações registrados no trabalho de campo, que a noção de estilo, como categoria nativa, remete à possibilidade de escolha, opondo-se à noção de moda, que, por sua vez, é associada à padronização, homogeneidade.

Sobre seguir a moda, I. nos conta que "às vezes é bom seguir, às vezes não. Eu sigo quando acho bonito, né. Quando acho que é mais o meu estilo, mas quando acho que não é legal, que não vai me cair bem, que não combina a roupa com a pessoa, eu nem coloco no corpo pra ver como fica."

O discurso da moda, no entanto, vem valorizando as noções de estilo/tendência como estratégia de incorporar a resistência à homogeneização, conforme atestado por Crane:

Já não se espera que os novos estilos cheguem a ser amplamente aceitos pelo público. Na indústria de moda de luxo francesa, fala-se de tendances (tendência) em lugar de moda, o que sugere sutis mudanças que exercerão influência discreta sobre o público, em vez de produzir poderosos efeitos catalizadores. (Crane, 2011: 191)

Tudo se passa como se o consumidor fosse livre para optar pelo estilo que desejasse, podendo percorrer as variadas possibilidades oferecidas pelo mercado de moda, de acordo com sua personalidade e individualidade. Essas possibilidades de "escolhas" são alimentadas com informações advindas de todos os lados, tanto no âmbito global como no local, que dialogam com base na ressignificação e no uso diário de estilos e/ou modas diversas. Os indivíduos, embebidos por um discurso que preconiza a liberdade e autonomia individuais, ${ }^{12}$ percebem na noção de estilo uma alternativa de indi-

10 Depoimento de I., 18 anos, estudante, concedido a esta pesquisa em 18 de dezembro de 2015.

11 Depoimento de I., 18 anos, estudante, concedido a esta pesquisa em 18 de dezembro de 2015.

12 Elementos muito presentes no discurso hegemônico acerca da cultura contemporânea, identificado, grosso modo, como neoliberal. A esse respeito, ver: Laval e Dardot (2013). 
vidualidade e liberdade, elegendo um discurso que combate a moda como inimiga da afirmação de particularidades. Como apontam Lavall e Dardot (2013), vivemos em uma era em que o cálculo individual e a escolha são preconizados como valores e requisitos para que o indivíduo desenvolva uma boa "performance" social. A "obrigação de escolher" se coloca como regra básica do jogo, no qual caberia ao indivíduo empreender uma "empresa de si", desenvolvendo habilidades calculistas enquanto se move entre oportunidades e busca as melhores alternativas para maximizar seu interesse próprio. Ou seja, cada um deve aprender a se tornar um sujeito "ativo" e "autônomo" na ação, e pela ação, que deve realizar sobre si mesmo. Assim, aprenderá sozinho a desenvolver "estratégias de vida" para incrementar seu capital humano e valorizá-lo da melhor maneira possível (...) Se essa ética neoliberal do "si mesmo" não se restringe às fronteiras da empresa, não é apenas porque o sucesso na carreira se confunde com o sucesso na vida, mas mais fundamentalmente porque o managment moderno busca "recrutar as subjetividades" com ajuda de controles e avaliações da personalidade, das disposições de caráter, das formas de ser, de falar, de se mover... (Lavall; Dardot, 2013: 342, tradução livre) $)^{13}$

Perspectivas como essas se contrapõem tanto ao discurso das instâncias que promovem a circulação e legitimação da moda como ao discurso dos consumidores, no qual a noção de estilo aparece desprovida de suas articulações com as esferas da produção e do mercado, como se o leque de possibilidades de escolhas colocado para as construções de estilos não fosse, por um lado, previamente definido e restrito por interesses da indústria e do mercado e, por outro, limitado pelo próprio habitus (Bourdieu, 2007), que, como matriz de percepção e ação, socialmente construída, define gostos, modos de usos e estilos de vida.

Os estilos de vida são, portanto, produtos dos habitus e, como tal, expressam "escolhas" realizadas com base em um leque de possibilidades colocados em cada um dos subespaços simbólicos que o compõem. Cada "escolha" guarda uma correspondência com as demais, revelando a trajetória do agente

13 No original: "Es decir, que cada uno debe aprender a convertirse em um sujeto "activo" y "autónomo" em y mediante la acción que debe llevar a cabo sobre si mesmo. Así aprenderá él solo a desplegar "estratégias de vida" para incrementar su capital humano y valorizarlo de la mejor manera posible (...) Si esta ética neoliberal del si mismo no se detiene en las fronteras de la empresa, no es solo porque el éxito de la carrera se confunde com uma vida lograda, sino más fundamentalmente todavia, porque el managment moderno persigue "enrolar a las subjetividades" com ayuda de controles y evaluciones de la personalidade, de las disposiciones del carácter, de las formas de ser, de hablar, de moverse..." (Lavall; Dardot, 2013: 342). 
e atestando o filtro subjetivo e a marca do indivíduo. Contudo, o referido leque se configura pelas limitações impostas pelos interesses da produção e dos agentes do mercado. Considerando esses pressupostos, discutiremos, a seguir, os discursos dos entrevistados relativos ao consumo de referências de moda de circulação global, enfocando suas apropriações, ressignificações e eventuais estratégias de distinção.

\section{Símbolos globalizantes: as apropriações de Réplicas e Originais}

Percebemos, durante o trabalho de campo, que eram muito recorrentes as referências à compra e ao uso de peças originais e/ou réplicas. Os discursos apreendidos, apesar de variarem, apontam para a mesma direção. De forma geral, a escolha pela réplica ocorre com base no desejo de possuir e exibir uma peça de "marca".

Quando nos referimos à "marca" e/ou "originais", estamos nos remetendo, especificamente, aos produtos de moda advindos do mercado globalizado, no qual as verdadeiras marcas são representadas por símbolos presentes em mercadorias detentoras de direitos de propriedade intelectual. "Os proprietários da marca possuem legitimidade social que se sustenta em princípios mercantis e políticos" (Pinheiro-Machado, 2009: 120). Nesse contexto, as "imitações", "falsificações" ou "réplicas" não autorizadas têm um caráter ilegítimo e criminoso. Entretanto, tal ilegitimidade não é tão rapidamente incorporada no âmbito social. Assim como nos apontou a pesquisa de campo, o uso de réplica não deslegitima o símbolo da marca, e o que importa é exibi-la, partilhando o símbolo, seja ele original ou não.

Desse modo, exibir o símbolo da marca é uma predisposição fundamental. Mostramos aos indivíduos entrevistados duas imagens - uma com uma camiseta preta com o símbolo da Nike bastante aparente - tomando toda a frente da peça - e outra, também preta, porém com um símbolo de tamanho bem discreto localizado perto das mangas - e perguntamos qual das peças escolheriam.

A primeira fala de todos os informantes apontou para a peça com o símbolo grande e bastante aparente: "Eu escolho o grande, porque mostra que é da Nike, já chega e já chama atenção" ${ }^{14}$ Sobre exibir o símbolo da peça de marca, J. disse que este "deve estar brilhante" ${ }^{15}$, para que seja logo avistado.

No entanto, logo em seguida, as falas foram se alterando, e os entrevistados passaram a afirmar que escolheriam a peça com o símbolo pequeno e discreto.

14 Depoimento de U., 18 anos, desempregado, concedido a esta pesquisa em 18 de dezembro de 2015.
15 Depoimento de J., 24 anos, cabelereira, concedido a esta pesquisa em 18 de dezembro de 2015 . 
Então, refizemos a questão e perguntamos qual das peças "as pessoas da comunidade" escolheriam, e, novamente, as respostas indicaram para o mesmo caminho inicial: todos os sujeitos entrevistados afirmaram que "os outros" optariam pela peça com a marca grande e aparente, como forma de exibir o uso de uma roupa de marca, e J. brincou que quanto aos "outros": "tem gente que coloca até a etiqueta pra fora"16 para mostrar que possui uma peça de marca.

A compra de peças originais, bem como a valorização da marca, foi relatada como preocupação "do outro" em todas as entrevistas, e notou-se que os entrevistados se colocam como não consumidores de marcas, apesar de, no decorrer das falas, notarmos certa valorização com relação a elas.

A. nos contou que "não liga pra roupas de marca", mas, segundo ela: "Só minha filha que é raridade eu dar as coisas pra ela, mas quando dou ela quer coisa boa, celular de mil reais essas coisas. (...) Ah quando eu tenho eu vou atrás, mas pra ela; eu não sou chegada a marca nenhuma" ${ }^{17}$.

M. nos relatou que quando jovem gostava muito de roupas de marca e, inclusive, chegou a gastar o salário de um mês comprando uma blusa da Adidas, porém afirma que atualmente não se importa com marca, mas que seu marido e seu filho se preocupam com isso ${ }^{18}$.

S. ${ }^{19}$ também relata que "tanto faz" se a roupa é de marca ou não, mas que para os jovens isso é importante. M. também disse que não se importa, mas que: "Aqui na comunidade as pessoas que querem comprar até compram réplica, mas a maioria é original, Nike, Reebok, Dakota pra mulher, Vizano. Eu não ligo tanto, mas meu marido é tudo de marca...." ${ }^{20}$

Esse distanciamento individual daquilo que é produto de marca apareceu com ainda mais intensidade quando tratamos da importância da moda no dia a dia dos entrevistados. Todos negaram se importar com questões relativas à moda, independentemente da idade. Sugerimos que tal negação se relaciona à anteriormente citada teoria da denegação, de Freud (1976 [1924]), ou seja, os indivíduos negam aquilo que já lhe foi negado por um contexto social capitalista que os exclui de um mercado específico.

16 Depoimento de J., 24 anos, cabelereira, concedido a esta pesquisa em 18 de dezembro de 2015.

17 Depoimento de A., 34 anos, diarista, moradora dos "predinhos", concedido a esta pesquisa em 30 de abril de 2015 .

18 Depoimento de N., 38 anos, desempregada, moradora dos barracos, concedido a esta pesquisa em 30 de abril de 2015 .

19 Depoimento de S., 47 anos, líder comunitária, concedido a esta pesquisa em 30 de julho de 2014.

20 Depoimento de M., 23 anos, dona de casa, concedido a esta pesquisa em 18 de dezembro de 2015. 
Interessante notar que, a todo momento, as respostas se contrapõem, revelando certa ambiguidade nos discursos. Assim, os indivíduos que há pouco diziam não se importar com roupas de marca afirmam que preferem uma réplica a uma peça "sem marca alguma", como forma de se aproximar do original - financeira e simbolicamente distante de suas realidades.

Perguntamos se entre duas camisetas brancas iguais, sem nenhuma estampa, sendo uma réplica da Nike e a outra "sem marca", qual os entrevistados escolheriam. As repostas foram as seguintes:

(a réplica) Ah porque é moda, né... tá na moda, né. A gente tem curiosidade de andar com a roupa da moda.... então se não pode comprar uma original compra uma imitação. (...) Porque se é igual, tá imitação da outra, não vou deixar de comprar aquela pra comprar uma que não seja nada. Vou comprar a imitação ${ }^{21}$.

(a réplica) É uma forma de substituir ${ }^{22}$.

R. também tem uma opinião parecida e afirma que escolheria a réplica, pois: "Pra quem não conhece, é uma original." ${ }^{23}$

Apesar de o original poder ser confundido com a réplica "por quem não conhece", se ampliarmos essa disposição veremos que a posição social ocupada pelo indivíduo que faz uso de determinada peça - seja original ou não - é um fator decisivo para a avaliação resultante do olhar externo. Ou seja, como nos ensinou Bourdieu (1996), a soma dos capitais - capital econômico, social e cultural - dos quais os indivíduos são possuidores, distinguem-nos e os posicionam no contexto social, e, sob as prerrogativas de uma luta constante por capitais, aquele que domina o campo possui credibilidade para usufruir de bens originais. $\mathrm{O}$ uso de réplicas por esses indivíduos - possuidores de um grande número de capitais - não é considerado habitual.

Portanto, se um jogador de futebol está fazendo uso de uma camiseta da Nike, a veracidade da marca não será contestada. Em contrapartida, se um indivíduo morador da favela fizer uso da mesma peça, esta será tida como falsificada, mesmo que não o seja.

21 Depoimento de M., 23 anos, dona de casa, concedido a esta pesquisa em 18 de dezembro de 2015.

22 Depoimento de N., 38 anos, desempregada, moradora dos barracos, concedido a esta pesquisa em 30 de abril de 2015 .

23 Depoimento de R., 52 anos, diarista, moradora de uma região a ser urbanizada, concedido a esta pesquisa em 30 de abril de 2015. 
Quem está usando (tal como quem está falando, DaMatta, 1981) é ainda um fator decisivo na luta de autenticidade extraclasses, e é isso que faz com que bens originais se passem por falsos e vice-versa, quando saem das lojas e ganham vida social. (Scalco; Pinheiro-Machado, 2010: 350).

Os produtos de luxo são restritos a uma elite, e as cópias são feitas para serem popularizadas, mesmo sendo, muitas vezes, demasiadamente parecidos.

Porém, especialmente no ramo das marcas de luxo, os cuidados com os detalhes - expresso no tempo e no custo da produção - é um definidor importante de autenticidade. Tais cuidados passam a ser um valor simbólico, enquadrado na categoria de qualidade. $\mathrm{O}$ valor simbólico agrega um fenomenal valor econômico. O fetichismo da mercadoria de uma bolsa Chanel, por exemplo, está baseado na relação de trabalho em que a funcionária da fábrica passa longos momentos terminando de costurar o produto à mão. Se não resistir aos testes, a bolsa será, irreversivelmente, queimada. (Pinheiro-Machado, 2010: 124)

A qualidade ${ }^{24}$ das réplicas foi contestada por todos os entrevistados, os quais relataram que essas peças não duram muito tempo por terem qualidade inferior; fato que serviu de justificativa para a compra eventual de produtos de marca. Nesse momento, é possível observar uma dinâmica dualista, na qual ocorre a negociação e o equilíbrio entre razões práticas e simbólicas, cálculo e hedonismo, dinheiro e amor, efemeridade e duração (Scalco; Pinheiro-Machado, 2010).

As réplicas se relacionam a produtos de curta duração, e, portanto, presentear com uma réplica pode ser considerado um ato desagradável, ao passo que, dar de presente uma peça original, de marca verdadeira associa-se ao sentimento verdadeiro e duradouro que se deseja compartilhar: "Se você gosta da pessoa tenta dar o melhor pra ela. Se você dar uma réplica pode não durar, então como você gosta muito da pessoa você quer que dure aquele presente então você dá uma roupa de marca." ${ }^{25}$

Além disso, presentear com uma peça original também se relaciona à noção de afeto e de sacrifício, já que, como nos contou M., não importa a dificuldade

24 Este discurso relacionado à qualidade é explicado por Scalco e Pinheiro Machado (2010): "conscientes de que as cópias podem alcançar uma imagem perfeita dos produtos originais, as empresas de marca de luxo sustentam seu diferencial através do discurso da qualidade. Uma réplica de um relógio Dior, por mais perfeito que seja, jamais terá seus 12 diamantes. Comerciantes de cópia possuem como arma o preço e acessibilidade do produto" (Pinheiro Machado, 2010: 124).

Depoimento de U., 18 anos, desempregado, concedido a esta pesquisa em 18 de dezembro de 2015. 
em encontrar a peça ou mesmo em pagar pelo preço dela quando se pretende mostrar um sentimento a uma pessoa: "Quando eu namorava com meu marido rodei tanto pra dar uma original pra ele. Réplica depois de casado. Original foi só pra conquistar." ${ }^{26}$

R. negou que comprasse roupas de marca ou até mesmo réplicas, mas nos contou que presenteou seu filho com um tênis da Nike que foi ao shopping comprar, pois ele "merecia" tal esforço financeiro: "No ano passado tive que comprar um tênis pro meu filho que ele queria muito, apesar que meus filhos não são ligados em cosias de marca, graças a Deus, mas como ele merece a gente faz um esforço." ${ }^{27}$

A fim de identificar a relação dos entrevistados frente a diversas marcas mundialmente conhecidas, mostramos para o grupo focal algumas imagens contendo os logotipos de marcas consideradas globais, como: Lacoste, Louis Vuitton, Quicksilver, BillaBong, Vans, DC, Chanel, Dior, Valentino, YSL, D\&G e Prada. Em proporções diferentes, é possível notar tanto no dia a dia da comunidade como nos pontos comerciais o uso e a venda de réplicas de algumas dessas marcas. No entanto, apesar disso, quando apresentados aos logotipos, os entrevistados pareceram não estar familiarizados com elas, em um primeiro momento. Alguns afirmaram não conhecer nenhuma das marcas - "da onde veio isso?"28 - enquanto outros começaram a reconhecer algumas delas, como a Louis Vuitton, que foi rapidamente relacionada à bolsa que alguns relataram já ter possuído em algum momento.

Muitas dessas marcas são extremamente famosas e importantes para um mercado consumidor da moda específico - no qual se inserem as camadas média e alta —, porém, pouco importam no universo estudado neste trabalho.

De fato, são as marcas relacionadas a esportes que se tornam popularmente reconhecidas nesse contexto. Quando mostramos os logotipos da Puma, Adidas e Nike, logo foram reconhecidos, e a eles foi conferido status de - nas palavras de J. - marcas "com cara da riqueza."

Essas marcas, além de serem diretamente relacionadas com o futebol, que atualmente lança grande parte dos ídolos populares, também têm grande participação nas mídias, o que lhes atribui legitimidade.

26 Depoimento de M., 23 anos, dona de casa, concedido a esta pesquisa em 18 de dezembro de 2015.

27 Depoimento de R., 52 anos, diarista, moradora de uma região a ser urbanizada, concedido a esta pesquisa em 30 de abril de 2015.

28 Depoimento de M., 23 anos, dona de casa, concedido a esta pesquisa em 18 de dezembro de 2015.

29 Depoimento de J., 24 anos, cabeleireira, concedido a esta pesquisa em 18 de dezembro de 2015. 
Esses logotipos logo foram associados a camisetas, chuteiras e bonés. Além disso, foi evidente o prestígio dado a essas marcas pelos sujeitos entrevistados, que as consideram "as mais to $p$ "30.

Ao realizar uma primeira análise desses relatos, é possível notar uma dualidade: ao mesmo tempo em que buscam pelo distanciamento do que é considerado supérfluo e pertencente a outros grupos sociais, também existe o desejo por usufruir daquilo.

Segundo a teoria sobre a difusão da moda de Simmel, "os novos estilos, inicialmente adotados pelas elites da classe alta, aos poucos se difundem para a classe média e, por fim, para a classe trabalhadora" (Crane, 2011: 179). Assim, os indivíduos pesquisados consumiriam os símbolos das marcas globais para imitar as classes superiores, e alguns discursos nos remetem, de fato, a essa teoria.

Perguntamos por que um dia desejaram e compraram uma roupa de marca original: "Porque era original e só as patricinhas tinham, eu morava aqui na comunidade, (...) eu também podia ter, só porque eu morava comunidade que eu não ia ter? Porque só quem tinha mais era as boyzinhas." ${ }^{31}$

J. relatou passar por uma situação parecida: "A minha história é quase igual a dela, comprei no shopping. Se elas podem eu também posso. Foi a mesma sensação dela, me senti patricinha um dia." ${ }^{32}$

Com base nas entrevistas realizadas podemos perceber que a apropriação de bens "de marca" não se articula ao desejo de pertencer a outra classe social. Ao enfocarmos este grupo de baixa renda, percebemos, tal como já haviam identificado Scalco e Pinheiro Machado, (2010) que, se há estratégia de distinção, ela é intraclasse e não extraclasse. Não se busca imitar ou parecer com as classes médias, mas, de certo modo, circular pelo seu universo, brincar com seus elementos, mas permanecer em seu próprio. Neste sentido, aproximamo-nos de outros trabalhos que enfocaram populações periféricas e também percebem a apropriação de elementos pertencentes a outros domínios culturais, que ganham um sentido próprio nos contextos locais, baseados na agência dos sujeitos (Mizrahi, 2014).

\section{Considerações finais}

Desde as primeiras sondagens exploratórias, quando caminhávamos pelas ruas do bairro, saltou-nos aos olhos os varais improvisados com camisetas

30 Depoimento de U., 18 anos, desempregado, concedido a esta pesquisa em 18 de dezembro de 2015 .

31 Depoimento de M., 23 anos, dona de casa, concedido a esta pesquisa em 18 de dezembro de 2015.

32 Depoimento de J., 24 anos, cabeleireira, concedido a esta pesquisa em 18 de dezembro de 2015. 
estampando grifes conhecidas. Em uma das situações, vimos um adolescente portando um boné da John John - marca renomada e cobiçada pelos jovens - em um quintal de "terra batida", com resquícios de ambiente rural, como criação de galinhas.

Essas observações nos reforçaram a percepção de que a discussão sobre consumo nas populações periféricas e de baixa renda é pertinente, contrariando algumas perspectivas que afirmam ser a abordagem desta temática inconcebível em grupos que dispendem toda a sua renda com os chamados produtos de necessidade básica, como alimentação, transporte e moradia. Este tipo de pressuposição desconhece as estratégias de aquisição que garantem a circulação das "coisas de marca", como chamadas por nossos interlocutores. Tais estratégias passam pela "feirinha da madrugada", que consiste num comércio clandestino em que são vendidos - a preços bem abaixo do mercado - produtos como óculos, bolsas, jeans e camisetas de grifes, bem como por bazares organizados pela associação de moradores do bairro, em que se comercializam roupas usadas e seminovas, doadas à associação.

Por fim, vale destacar um dos principais aspectos discutidos nesta pesquisa: os sentidos do consumo e a tão propalada lógica da imitação-distinção como motor propulsor deste. Percebemos que o consumo de grifes ou roupas e acessórios de marcas é mais valorizado entre os jovens e, dentre eles, não tem o sentido de imitar para ser reconhecido como de outra classe social. Há um reconhecimento da lógica da imitação-distinção, mas ao se apropriarem dos bens marcadores de distinção não desejam, intencionalmente, pertencer a um outro universo social; esta apropriação tem o sentido de experimentação e, assim como identificado em outros estudos sobre o consumo popular, se ocorre distinção social, ela é apenas intraclasse, ou seja, ocorre no jogo de disputas simbólicas internas ao grupo, e não carrega o sentido de exclusão da sua própria condição.

\section{Referências}

APPADURAI, Arjun. Disjunção e diferença na economia cultural global. In:

FEATHERSTONE, Mike. Cultura Global. Nacionalismo, globalização e modernidade.

Petrópolis, Ed. Vozes, 1990.

BAUDRILLARD, Jean. Sociedade de consumo. Lisboa, Edições 70, 1985.

. O Sistema de objetos. São Paulo, Ed. Perspectiva, 1973.

BOURDIEU, Pierre. Coisas Ditas. São Paulo: Ed. Brasiliense, 2004.

. Razões Práticas. Sobre a teoria da ação. Campinas, Ed. Papirus, 1996. 
. O Poder Simbólico. Rio de Janeiro, Bertrand Brasil, 2004.

. A distinção: crítica social do julgamento. São Paulo, EDUSP, Porto Alegre, Zouk, 2007.

. A economia das trocas simbólicas. São Paulo, Ed. Perspectiva, 1982.

CANCLINI, Néstor García. Consumidores e cidadãos: conflitos multiculturais da globalização. Rio de Janeiro, Editora UFRJ, 2008.

CASTRO, Ana Lucia; CAPELARO, Ana Luíza de Souza. Corpo, Consumo cultural e construção da aparência: estudo comparativo acerca da relação de diferentes grupos juvenis com a moda. XIV Congresso Brasileiro de Sociologia. Rio de Janeiro, 2009.

. Sentidos do consumo e fronteiras simbólicas: uma etnografia entre grupos de baixa renda em um município da Grande São Paulo, Brasil. Etnográfica. Lisboa, v. 20, n. 1, 2016, pp. 101-117.

CRANE, Diana. A moda e seu papel social: classe, gênero e identidade das roupas. São Paulo, Ed. SENAC SP, 2006.

. Ensaios sobre moda, arte e globalização cultural. São Paulo, Ed. Senac, 2011.

DE CERTEAU, Michel. A invenção do cotidiano: artes de fazer. Rio de Janeiro, Ed. Vozes, 1994.

DOUGLAS, Mary.; ISHWOOD, Baron. O mundo dos bens: para uma antropologia do consumo. Rio de Janeiro, Ed. UFRJ, 2004.

FREUD, Sigmund. A negativa. In: Edição Standard Brasileira das Obras Completas de Sigmund Freud. 2. ed. Rio de Janeiro, Ed. Imago, 1976 (1924).

FONSECA, Claudia. Classe e a recusa etnográfica. In: FONSECA, Claudia e BRITES, Jurema (Orgs.). Etnografias da Participação. Santa Cruz do Sul, EDUNISC, 2006.

LAVAL, Christian.; DARDOT, Pierre. La nueva razón del mundo. Ensayo sobre la sociedad neoliberal. Barcelona, Gedisa, 2013.

LEITÃO, Débora. Brasil à moda da casa: imagens da nação na moda brasileira contemporânea. Tese de Doutorado em Antropologia Social. Instituto de Filosofia e Ciências Humanas, UFRGS, Porto Alegre, 2007.

MARTÍN-BARBERO, Jesús. Dos meios às mediações: comunicação, cultura e hegemonia. Rio de Janeiro, UFRJ, 1997.

MILLER, Daniel. Pobreza da moralidade. Antropolítica: Revista Contemporânea de Antropologia e Ciência Política. n. 17, 2004, pp. 21-43.

. Teoria das compras: o que orienta as escolhas dos consumidores. São Paulo, Nobel, 2002.

MIZRAHI, Mylene. A estética funkcarioca: criação e conectividade em Mr. Catra. Rio de Janeiro, 7 Letras, 2014.

MONTERO, Paula (Org.). Deus na Aldeia: missionários, índios e mediação cultural. São Paulo, Globo, 2006. 
ORTIZ, Renato. Mundialização e Cultura. São Paulo, Ed. Brasiliense, 1994. . Anotações sobre o universal e a diversidade. Revista Brasileira de Educação. v. 12, n. 34, 2007.

PINHEIRO-MACHADO, Rosana. Made in China: Produção e circulação de mercadorias no circuito China-Paraguai-Brasil. Tese de Doutorado. Programa de Pós-Graduação em Antropologia Social da Universidade Federal do Rio Grande do Sul. Porto Alegre, 2009.

SAHLINS, Marshall. O pessimismo sentimental e a experiência etnográfica: porque a cultura não é um objeto em vias de extinção. Parte I. Mana. v. 3, n. 1, 1997. . La pensée bourgeoise. In: SAHLINS, Marshall. Cultura e razão prática. Rio de Janeiro, Jorge Zahar, 2003.

. Cosmologias do capitalismo: o setor trans-pacífico do "sistema mundial". In: Cultura na Prática. Rio de Janeiro, Editora UFRJ, 2004.

SCALCO, Lucia Mury; MACHADO, Rosana Pinheiro. Os sentidos do real e do falso: o consumo popular em perspectiva etnográfica. Revista de Antropologia. São Paulo, USP, v. 53, n. 1, 2010.

SIMMEL, Georg. Filosofia da Moda e outros ensaios. Lisboa, Ed. Texto e Grafia, 2008.

VELHO, Gilberto; KUSCHNIR, Karina. (Orgs) Mediação, Cultura e Política. Rio de Janeiro, Aeroplano, 2001.

Recebido em 01/06/2016

Aprovado em 30/05/2019

\section{Como citar este artigo:}

CASTRO, Ana Lucia de e HADDAD, Beatriz Sumaya M. "Moda, eu faço a minha”: a circulação de símbolos globais de moda entre grupos de baixa renda. Contemporânea - Revista de Sociologia da UFSCar, v. 9, n. 1, jan.- jun. 2019, pp. 229-252. 